\title{
Effects of storage time and temperature on the antimony and some trace element release from polyethylene terephthalate (PET) into the bottled drinking water
}

\author{
Ebrahim Molaee Aghaee ${ }^{1}$, Mahmood Alimohammadi2 ${ }^{2}$, Ramin Nabizadeh², Gholamreza Jahed khaniki², \\ Simin Naseri ${ }^{2,3}$, Amir Hossein Mahvi ${ }^{2,3}$, Kamyar Yaghmaeian ${ }^{2}$, Hassan Aslani ${ }^{2}$, Shahrokh Nazmara², \\ Babak Mahmoudi ${ }^{2}$ and Maryam Ghani ${ }^{2}$
}

\begin{abstract}
Background and objectives: Heavy metals are considered as one of the major contaminants that can enter into the bottled waters. Antimony (Sb) is a contaminant, which may leach from the polyethylene terephthalate (PET) bottles into the water. The aim of this study was to investigate the content of antimony and other trace elements in bottled waters which was kept in varied storage conditions and temperatures.

Materials and methods: Five time-temperature treatments were carried out on five different brands of commercially available bottled waters. Heavy metal measurement was performed by Inductively Coupled Plasma-Atomic Emission Spectroscopy (ICP-AES) method. Analysis of the collected data was processed by SPSS software.

Results: Antimony concentration was the main concern in our study. The concentrations increased in each of the sample during storage period at all temperatures. The results for different conditions were as follow: at $40^{\circ} \mathrm{C}$, in outdoor and at room temperature the Sb concentrations were below the MCLs, i e. 6 ppb. However, at $65^{\circ} \mathrm{C}$ and $80^{\circ} \mathrm{C}$ for longer storage times $\mathrm{Sb}$ concentration exceeded the $\mathrm{MCLs}$, and variations between the samples were significant $(p \leq 0.05)$. Storage time and temperature effects on the content of some other trace elements such as Al, Fe were also significant ( $p \leq 0.05)$.
\end{abstract}

Conclusion: By increasing the duration of storage time and temperatures, antimony leaching from the PET bottles into the bottled water increased. The concentration of Al demonstrated an increase in higher temperatures and storage duration, whereas the content of Fe demonstrated no significant differences.

Keywords: PET, Bottled water, Antimony, Trace elements

\section{Introduction}

Consumption of bottled water has become increasingly popular worldwide. Population growth and lack of access to appropriate drinking water has also increased use of bottled waters; and in some areas, some major concerns to the consumers are environmental pollutants and its adverse effects on the local water supply, as well as, a number of the local municipality water irregularities,

\footnotetext{
* Correspondence: m_alimohammadi@tums.ac.ir

${ }^{2}$ Department of Environmental Health Engineering, School of Public Health,

Tehran University of Medical Sciences, Tehran, Iran

Full list of author information is available at the end of the article
}

such as off odor and taste of the water, high amount of fluoride and chloride. On the other hand, people with immunity system deficiency require more safe drinking water. Moreover, it is believed that bottled water is safer and has higher quality than other water resources which increased its consumption [1-3]. Hence, higher standards and quality control measures are required on the safety, chemical and microbial properties of the bottled waters. According to the World Health Organization (WHO), over 1.8 million people, particularly children, die annually due to water borne diseases, which have been, and is one 
of the leading and still prevalent mortality causes worldwide $[4,5]$.

Antimony, titanium or germanium compounds are used as catalysts in the manufacturing of polyethylene terephthalate (PET) bottles, where polymerization of terephthalic acid monomers and ethylene glycol occurs. Among these, Antimony trioxide is one of the main catalysts used, and the amount of Antimony trioxide found in the bottles varies between $100-300 \mathrm{mg} / \mathrm{kg}$ [6]. Antimony is regarded as one of the major drinking water contaminants, which exceeds the maximum contaminant level (MCL), i.e. $6 \mathrm{ppb}$, under a number of conditions. Short term exposures to the levels higher than MCL, can cause side effects such as nausea, vomiting and diarrhea. Higher blood cholesterol and lower blood sugar are other side effects when exposed for a longer period of time [7]. According to Shotyk and Krachler high storage temperatures and sunlight irradiation could increase the $\mathrm{Sb}$ release into the bottled water [8].

Epidemiological studies revealed a significant link between diseases and the presence of trace toxic elements such as $\mathrm{As}, \mathrm{Cd}, \mathrm{Pb}$ and $\mathrm{Sb}$ in bottled waters, as well as the high amounts of essential micronutrients such as $\mathrm{Zn}$, Se and Co. Although, some trace elements such as $\mathrm{Cr}, \mathrm{Co}$ and Se are essential for human life, these mineral if consumed in higher rates than the suggested required daily(RD) amounts can be harmful $[9,10]$.

Due to a considerable increase in the PET bottled water consumption worldwide, the purpose of this study was to investigate the trace element contents in bottled waters and the conditions, which affect the release of $\mathrm{Sb}$ and/or other trace elements into the water.

\section{Materials and methods}

Five different popular brands of bottled water with the highest rate of consumption were purchased from the local grocery markets, in Tehran, Iran. The main criteria for selecting the brands in this study, was their production in different regions of Iran and different environments. The five storage conditions designed for the investigation of the samples were, storage at room temperature $(25 \pm$ $\left.2.6^{\circ} \mathrm{C}\right)$, outdoors and sunlight $\left(31 \pm 4.6^{\circ} \mathrm{C}\right)$ and $40^{\circ} \mathrm{C}$ and the experiment intervals were defined as follows, weeks 0 (immediately after receiving), 1, 2, 4, 6 and 8 were performed. Storage at $65^{\circ} \mathrm{C}$, and the experiments was done in days zero (immediately after receiving), 3, 7 and weeks 2 , 4 and 6 . Storage at $80^{\circ} \mathrm{C}$ at test days zero (immediately after receiving), 1, 2, 3, 4 and 7 was considered for the other storage condition. In the defined intervals for each temperature condition, $0.5 \mathrm{~L}$ samples were acidified with $1 \mathrm{~mL} 65 \%$ nitric acid to prevent sedimentation and then were digested and placed on an electrical heater to obtain a concentrated volume of $25 \mathrm{~mL}$. Furthermore, in order to detect the very low trace amounts of the elements, the condensation process was carried out at a very low temperature over a long period of time to prevent boiling of the samples. For short-term storage, i e. before sample injection to ICP-AES (model Spectro ARCOS.), and in order to prevent any variation in trace elements concentrations $\mathrm{pH}$ of the samples were lowered to 2 by using a pure $65 \%$ nitric acid. Chemical examinations were performed by Ion Chromatography (IC) for anions and cations, additional procedures were performed according to the Standard Methods for the Examination of Water \& Wastewater (APHA 21st Ed.). Statistical analyses was performed using the SPSS (11.5) software. A probability level of $p<0.05$ was considered statistically significant.

\section{Results}

Chemical properties of all five brands of the different bottled waters were measured for a better consideration of the examined samples. Both labeled data and analyzed characteristics are presented in Table 1 . All samples $\mathrm{pH}$ were in the range from 7.2 to 7.9 which specified by the labels as well as measurements.

Content of trace metals in the bottled water samples at the initial stage of this study are illustrated in Table 2.

Antimony concentrations, as the main trace element of the study, in all the samples at the day zero and at the initial stages of the examinations were below the MCL (6 ppb), but the levels were higher for samples 3 and 4 than others samples $(\mathrm{p} \leq 0.05)$. Under the outdoor and sunlight condition with the average temperature of $31 \pm 4.1^{\circ} \mathrm{C}$, the concentration of $\mathrm{Sb}$ increased in all samples over time. At room temperature storage $\left(25 \pm 2.6^{\circ} \mathrm{C}\right)$ as well as in $40^{\circ} \mathrm{C}$ condition, the trend of changes were similar to the outdoor conditions and variations were insignificant, in both cases ( $p>0.05)$. The Sb content of bottled waters was still lower than the MCL at the end of the study (after 8 weeks) for the outdoor storage, the interior storage and $40^{\circ} \mathrm{C}$ storage conditions. Our findings demonstrated that there was a high correlation between the $\mathrm{Sb}$ initial concentrations and its amounts during the study. By considering the fact that $\mathrm{Sb}$ concentration changes was similar at the three storage conditions and the trends were the same Figure 1 demonstrates the average $\mathrm{Sb}$ changes for the storage duration in the three above mentioned conditions.

Antimony concentrations at $65^{\circ} \mathrm{C}$ increased over the MCL following the two weeks storage period for samples 3 and 4, whereas in the case of other samples it was still lower than the MCL by the end of the study (Figure 2).

In addition, as illustrated in Figure 3, at $80^{\circ} \mathrm{C}$, Sb concentration increased over the MCL in the second day of the storage time for samples 3 and 4, while for the other samples it was observed in the day three.

At the end of the study, the highest concentration for $\mathrm{Sb}$ was recorded at $80^{\circ} \mathrm{C}$ storage conditions, and as can 
Table 1 Physicochemical properties of bottled water samples

\begin{tabular}{lllllllllll}
\hline Brand no. & $\mathbf{F}$ & $\mathbf{C l}$ & $\mathbf{N O}_{\mathbf{2}}$ & $\mathbf{N O}_{\mathbf{3}}$ & $\mathbf{S O}_{\mathbf{4}}$ & $\mathbf{N a}$ & $\mathbf{K}$ & $\mathbf{C a}$ & $\mathbf{M g}$ & $\mathbf{p H}$ \\
\hline 1 & $0.07 \pm 0.03$ & $1.77 \pm 0.04$ & 0 & $4.02 \pm 0.14$ & $9.26 \pm 0.06$ & $3.9 \pm 0.16$ & $0.21 \pm 0.007$ & $42.7 \pm 19.37$ & $3.99 \pm 0.25$ & $7.42 \pm 0.06$ \\
Label & 0.2 & 6 & 0 & 7 & 10 & 5 & 1 & 29.6 & 4 & 7.3 \\
2 & $0.27 \pm 0.007$ & $8.75 \pm 0.02$ & 0 & $14.4 \pm 0.42$ & $26.25 \pm 0.21$ & $8.44 \pm 0.0$ & $0.82 \pm 0.17$ & $39.45 \pm 36.5$ & $18.85 \pm 0.35$ & $7.59 \pm 0.09$ \\
Label & 0.23 & 16.4 & 0 & 14 & 21 & 10.8 & 1.37 & 62.7 & 20.3 & 7.5 \\
3 & $0.07 \pm 0.02$ & $1.09 \pm 0.03$ & 0 & $3.95 \pm 0.23$ & $6.32 \pm 0.1$ & $0.98 \pm 0.12$ & $0.31 \pm 0.03$ & $31.95 \pm 2.47$ & $7.39 \pm 0.53$ & $7.67 \pm 0.05$ \\
Label & 0.07 & 6 & 0 & 7 & 3 & 1 & 0.1 & 32.1 & 7.61 & 7.6 \\
4 & $0.12 \pm 0.007$ & $0.64 \pm 0.02$ & 0 & $2.44 \pm 0.21$ & $20.35 \pm 0.21$ & $4.02 \pm 0.05$ & $1.59 \pm 0.01$ & $0.01 \pm 0.007$ & $0.0 \pm 0.007$ & $7.29 \pm 0.07$ \\
Label & 0.11 & 0.7 & 0 & 2.3 & 19 & 4.7 & 1.9 & 9.8 & 2.3 & 7.2 \\
5 & $0.15 \pm 0.01$ & $4.27 \pm 0.1$ & 0.06 & $12 \pm 0.14$ & $24.85 \pm 0.07$ & $10.7 \pm 0.14$ & $0.7 \pm 0.02$ & $106.5 \pm 21.92$ & $19.5 \pm 0.56$ & $7.42 \pm 0.07$ \\
Label & 0.2 & 6.1 & 0 & 7.5 & 10.6 & 10.5 & 0.6 & 56.4 & 15.4 & 7.4 \\
EPA,2002 & 2 & $250^{\mathrm{a}}$ & 3.3 & 44 & $250^{\mathrm{a}}$ & - & - & - & - & $6.5-8.5^{\mathrm{a}}$ \\
\hline
\end{tabular}

${ }^{\mathrm{a} S e c o n d a r y ~ M a x i m u m ~ C o n t a m i n a n t ~ L e v e l ~(S M C L) . ~}$

Table 2 Trace metals content of bottled water samples

\begin{tabular}{|c|c|c|c|c|c|c|c|}
\hline Metal/Brand & Unit & 1 & 2 & 3 & 4 & 5 & EPA (2002) \\
\hline$\overline{\mathrm{Al}}$ & $\mathrm{ppb}$ & $3.82 \pm 0.03$ & $6.17 \pm 0.45$ & $12.77 \pm 0.74$ & $7.52 \pm 1.23$ & $6.67 \pm 0.24$ & $200^{b}$ \\
\hline As & $\mathrm{ppb}$ & $N . D^{a}$ & N.D & N.D & $3.37 \pm 1.02$ & N.D & 10 \\
\hline B & $\mathrm{ppb}$ & $14.17 \pm 0.95$ & $25.97 \pm 1.09$ & $10.4 \pm 1.48$ & $35.52 \pm 2.93$ & $23.5 \pm 1.76$ & - \\
\hline $\mathrm{Be}$ & $\mathrm{ppb}$ & N.D & N.D & N.D & N.D & N.D & 4 \\
\hline $\mathrm{Ba}$ & ppm & N.D & $25.02 \pm 2.08$ & $10.37 \pm 1.23$ & $31.35 \pm 4.10$ & $31.47 \pm 2.86$ & 2 \\
\hline $\mathrm{Cd}$ & $\mathrm{ppb}$ & N.D & N.D & N.D & N.D & N.D & 5 \\
\hline Co & $\mathrm{ppb}$ & N.D & N.D & N.D & N.D & N.D & - \\
\hline $\mathrm{Cr}$ & $\mathrm{ppb}$ & $0.17 \pm 0.03$ & $0.17 \pm 0.09$ & N.D & $0.20 \pm 0.07$ & $0.19 \pm 0.05$ & 100 \\
\hline $\mathrm{Cu}$ & $\mathrm{ppb}$ & $2.25 \pm 0.56$ & $4.27 \pm 1.16$ & $2.07 \pm 0.53$ & $3.4 \pm 0.77$ & $7.92 \pm 0.88$ & $1^{\mathrm{b}}-1.3 p p m^{c}$ \\
\hline $\mathrm{Fe}$ & $\mathrm{ppb}$ & $1.57 \pm 0.38$ & $1.55 \pm 0.42$ & $2.77 \pm 0.53$ & $2.4 \pm 0.63$ & $5.77 \pm 0.74$ & $300^{b}$ \\
\hline $\mathrm{Hg}$ & $\mathrm{ppb}$ & N.D & N.D & N.D & N.D & N.D & 2 \\
\hline $\mathrm{Li}$ & $\mathrm{ppb}$ & N.D & $2.15 \pm 0.56$ & $0.57 \pm 0.24$ & $2.95 \pm 0.42$ & $0.62 \pm 0.17$ & - \\
\hline $\mathrm{Mn}$ & $\mathrm{ppb}$ & N.D & N.D & N.D & N.D & N.D & $5^{\mathrm{b}}$ \\
\hline Mo & $\mathrm{ppb}$ & N.D & N.D & N.D & N.D & N.D & - \\
\hline $\mathrm{Ni}$ & $\mathrm{ppb}$ & $1.5 \pm 0.35$ & $1.17 \pm 0.38$ & $0.37 \pm 0.10$ & $5.72 \pm 1.52$ & $1.47 \pm 0.38$ & 100 \\
\hline$P$ & $\mathrm{ppb}$ & $2.1 \pm 0.35$ & $1.9 \pm 0.63$ & $1.6 \pm 0.35$ & $1.85 \pm 0.35$ & $1.9 \pm 0.28$ & - \\
\hline $\mathrm{Pb}$ & $\mathrm{ppb}$ & $0.35 \pm 0.07$ & N.D & N.D & $0.75 \pm 0.14$ & N.D & 10 \\
\hline $\mathrm{Sb}$ & $\mathrm{ppb}$ & $0.64 \pm 0.05$ & $0.68 \pm 0.09$ & $1.41 \pm 0.12$ & $1.85 \pm 0.19$ & $0.44 \pm 0.04$ & 6 \\
\hline $\mathrm{Se}$ & $\mathrm{ppb}$ & $0.36 \pm 0.07$ & $0.47 \pm 0.10$ & $0.35 \pm 0.07$ & $0.38 \pm 0.04$ & $0.40 \pm 0.14$ & 5 \\
\hline Sn & $\mathrm{ppb}$ & $0.22 \pm 0.03$ & $0.27 \pm 0.10$ & $0.30 \pm 0.21$ & $0.97 \pm 0.38$ & $0.48 \pm 0.09$ & - \\
\hline $\mathrm{Sr}$ & $\mathrm{ppb}$ & $28.35 \pm 1.62$ & $49.77 \pm 1.44$ & $47.62 \pm 1.59$ & $36.22 \pm 2.51$ & $49.65 \pm 4.45$ & - \\
\hline $\mathrm{Ti}$ & $\mathrm{ppb}$ & N.D & N.D & N.D & N.D & N.D & - \\
\hline V & $\mathrm{ppb}$ & $0.42 \pm 0.10$ & $0.53 \pm 0.16$ & N.D & $2.55 \pm 0.98$ & N.D & - \\
\hline $\mathrm{Zn}$ & $\mathrm{ppb}$ & $36.15 \pm 6.57$ & $3.30 \pm 0.77$ & $2.12 \pm 0.88$ & $25.62 \pm 2.86$ & $9.37 \pm 1.30$ & $5 \mathrm{ppm}^{\mathrm{b}}$ \\
\hline
\end{tabular}

${ }^{\mathrm{a} N o t}$ Detected.

${ }^{\mathrm{b}}$ Secondary Maximum Contaminant Level (SMCL).

'Action Level. 


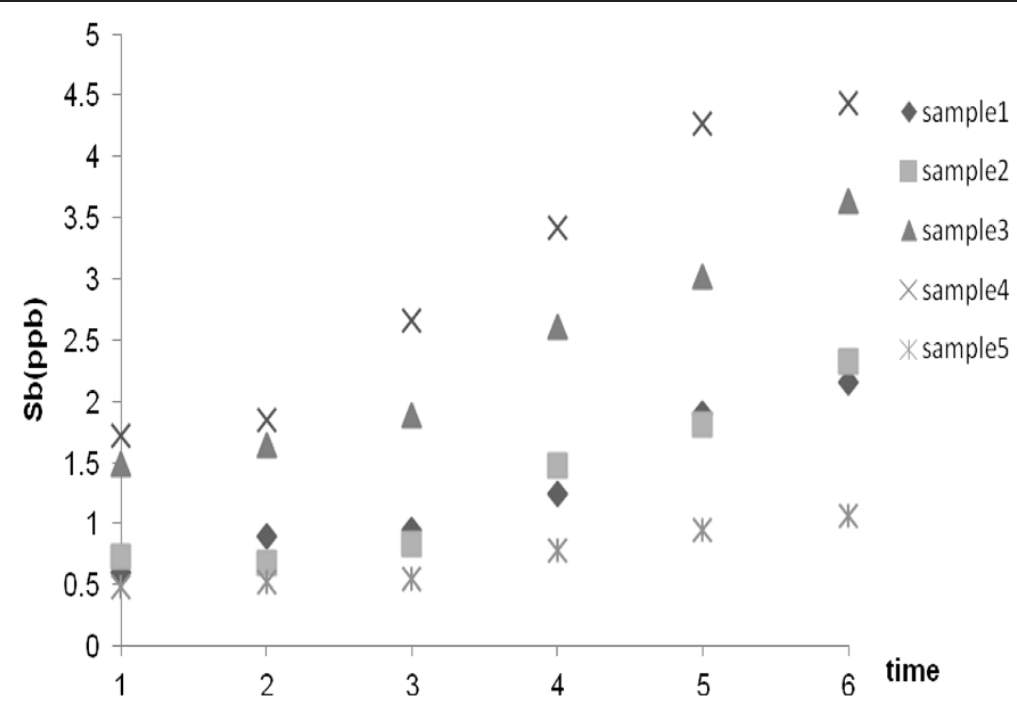

Figure 1 Antimony concentration changes during storage (outdoor, room and $40^{\circ} \mathrm{C}$ ).

be seen in Figure 4 the lowest concentration was observed for outdoor storage room and at the $40^{\circ} \mathrm{C}$ storage temperature.

Storage time and temperature effects on the $\mathrm{Al}$ concentrations were significant, particularly for the samples stored at $65^{\circ} \mathrm{C}$ and $80^{\circ} \mathrm{C}(\mathrm{p} \leq 0.05)$ which demonstrated a relevant increase during storage time. In case for Fe concentration the storage time and temperature effect was significant, mainly for the samples stored at $80^{\circ} \mathrm{C}(\mathrm{p} \leq 0.05)$, and demonstrated a relevant decrease during storage time. Other trace metals measured in this study included, As, B, $\mathrm{Ba}, \mathrm{Cr}, \mathrm{Cu}, \mathrm{Ni}, \mathrm{Pb}, \mathrm{Se}, \mathrm{Sn}, \mathrm{Sst}, \mathrm{Va}$ and $\mathrm{Zn}$. These elements showed no statistically significant differences $(p>0.05)$ for storage conditions. The elements $\mathrm{B}, \mathrm{Cr}, \mathrm{Cu}, \mathrm{Ni}, \mathrm{Se}, \mathrm{Sn}, \mathrm{St}$ and $\mathrm{Zn}$ displayed significant variations $(\mathrm{p} \leq 0.05)$ in each time zone and each temperature storage condition. B, Cr, $\mathrm{Cu}$ and $\mathrm{Sn}$ concentrations decreased in their time zones in all five temperature storage conditions, while $\mathrm{Ni}$ and $\mathrm{St}$ demonstrated a slightly increase in their time zone in each temperature storage condition. Selenium and $\mathrm{Zn}$ contents displayed both an increasing and decreasing trend by the storage time and at the different temperatures.

The elements Be, Cd, Co, Hg, Mn, Mo and Ti concentrations were below detection limit at all the storage conditions.

\section{Discussion}

Antimony and other trace element concentrations in the samples that were measured at the beginning of the study were all below the promulgated standards, except

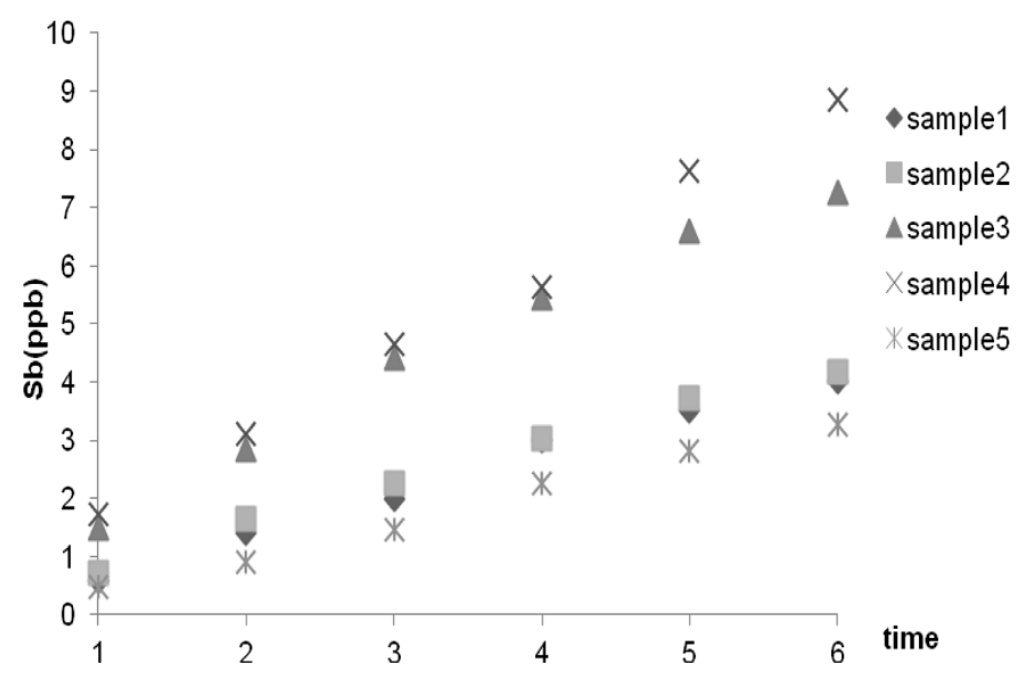

Figure $2 \mathrm{Sb}$ average concentration changes during storage $\left(65^{\circ} \mathrm{C}\right)$. 


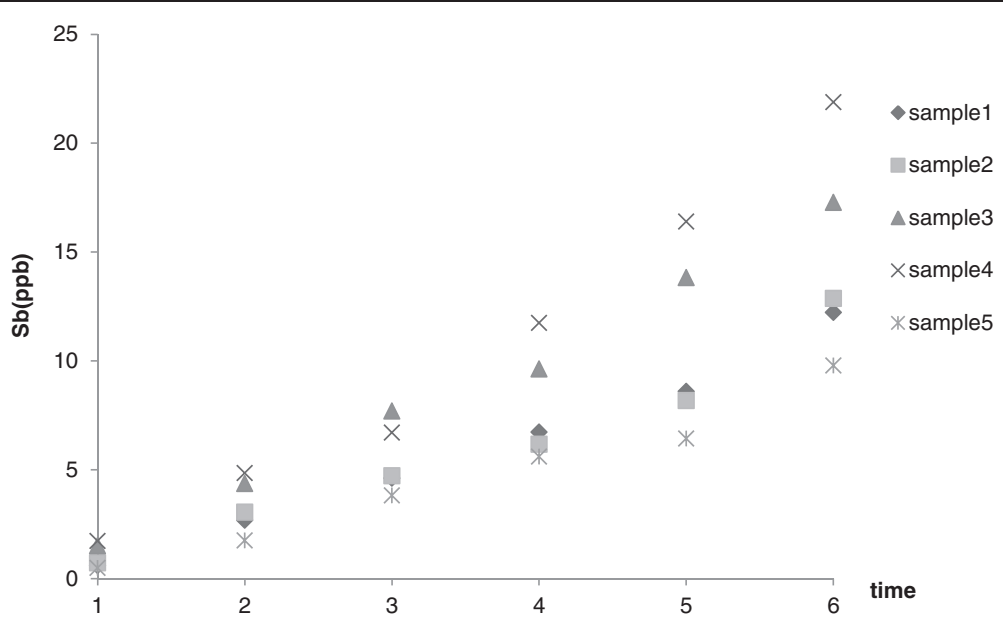

Figure $3 \mathrm{Sb}$ average concentration changes during storage $\left(80^{\circ} \mathrm{C}\right)$.

for Barium. Higher temperatures and longer storage times had a substantial effect $(\mathrm{p} \leq 0.05)$ on the increase of $\mathrm{Sb}$ and $\mathrm{Al}$ concentrations, while, a decrease was observed in case for Fe.

Westerhoff et al. [7] showed that high storage temperatures and sunlight exposure increased the leakage of antimony into the bottled waters. Antimony concentration in samples was $0.095-0.521 \mathrm{ppb}$ which was lower than that MCL recommended by the United States Environmental Agency (USEPA). The initial mean concentrations were $0.195 \pm 0.116 \mathrm{ppb}$, and after 3 monthas period at $22^{\circ} \mathrm{C}$ rose to $0.226 \pm 0.160 \mathrm{ppb}$. The amounts of $\mathrm{Sb}$ exceeded the MCL in the following conditions: $60^{\circ} \mathrm{C}$ in 176 days, $65^{\circ} \mathrm{C}$ in 38 days, $70^{\circ} \mathrm{C}$ in 12 days, $75^{\circ} \mathrm{C}$ in 4.7 days, $80^{\circ} \mathrm{C}$ in 2.3 days and $85^{\circ} \mathrm{C}$ in 1.3 days [7].
In this study, the average $\mathrm{Sb}$ concentrations were approximately $1.01 \pm 0.59 \mathrm{ppb}$ at the initial stage of the experiments, and by the end of the study (after 8 weeks) at room temperature $\left(25 \pm 2.6^{\circ} \mathrm{C}\right)$ rose to $2.54 \pm 1.58 \mathrm{ppb}$. In case of $65^{\circ} \mathrm{C}$, samples 3 and 4 which had the highest initial Sb content, after a two week periods exceeded the MCLs. while the other samples remained below the MCL. Whereas, as the temperature rose to $80^{\circ} \mathrm{C}$ after two days the $\mathrm{Sb}$ amounts exceeded the MCL for samples 3 and 4 , while for the other samples it was observed after day three.

Various experiments by Xiaoliang Cheng et al. [6] demonstrated that 16 trace elements including Sb were leaked into the bottled waters tested in the following conditions, cooling with ice-cold water, warming by boiling,

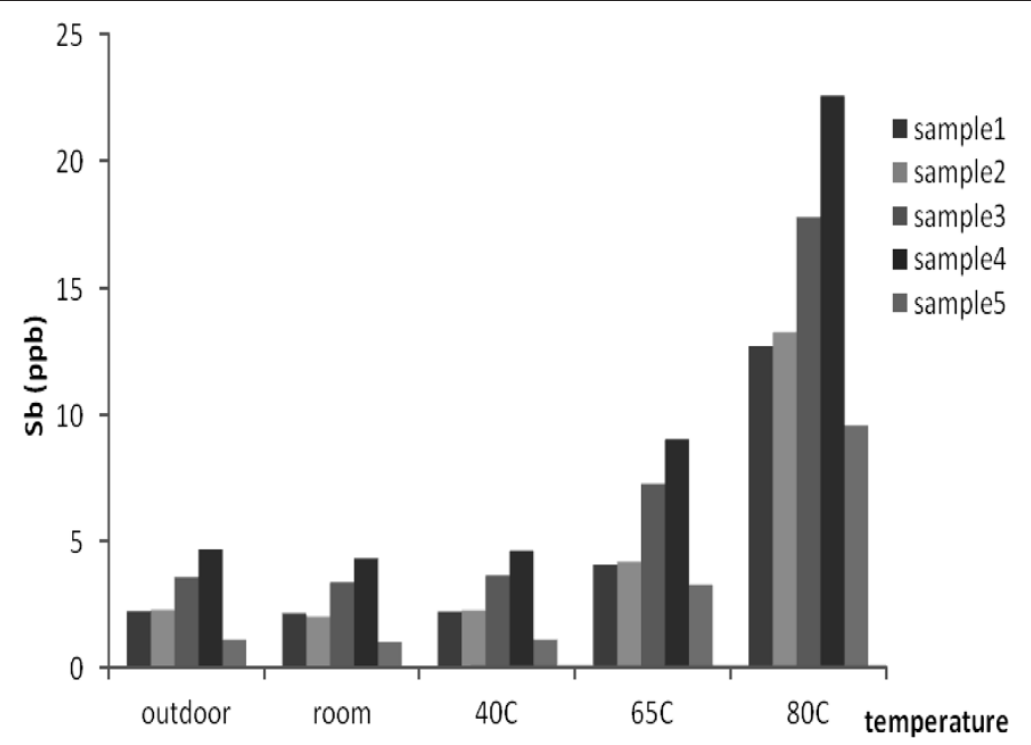

Figure 4 Concentration of $\mathrm{Sb}$ in the samples at the end of each storage condition. 
microwave, incubation at low $\mathrm{pH}$, outdoor with sunlight irradiation and storage inside the automobiles. The study established that warming by boiling and microwave could considerably augment the leaching process of $\mathrm{Sb}$ into water and in some cases exceeded the MCL levels. However, both incubation at low $\mathrm{pH}$ and also cooling with ice-cold water, revealed no significant effects; while the outdoor with sunlight irradiation and sunlight exposure, and the storage inside automobiles increased the leakage, but still was below the required MCLs [6].

The results revealed that minor leakage of $\mathrm{Sb}$ from PET bottles was due to plastic surface pollution at some stages of manufacturing process; while any major leakage was due to the changes in the bottle's storage conditions. The effect of various storage conditions on the leakage of $\mathrm{Sb}$ in the remaining 15 samples were not considerable and/or far below the recommended MCLs in all samples. Conversely, in this study, an increase in $\mathrm{Al}$ concentration was observed.

According to Shotyk et al. [11] the comparison between the natural aggregates of $\mathrm{Sb}$ in the underground waters versus the PET bottled waters (same water before and after bottling) indicated Sb leakage from these bottles. It was established that $\mathrm{Sb}$ content of the bottled was 30 times higher than the water in the glass container [11]. Keresztes et al. [12] studied ten different brands of pure and sparkling waters. The study demonstrated that the content of $\mathrm{Sb}$ in the sampled bottles was $0.03-0.1 \mathrm{ppt}$, which increased at room temperature, and in darkness. The study also revealed that light and temperature exposures could raise the concentration levels of $\mathrm{Sb}$ [12].

A study performed by Guler et al. [13] demonstrated that the levels of $\mathrm{Sb}$ in the various samples were higher than the Turkish legislative limits; $24 \%$ of natural spring water samples (24 out of 100$), 28.6 \%$ of natural mineral water samples ( 2 out of 7 ) and $54.4 \%$ of drinking water samples ( 6 out of 11). The present study, analyzed Ba concentration at the initial stage of the study in 4 samples, as illustrated in Table 2, the results were higher than USEPA recommended MCL level [13].

The concentrations of Sb's in 132 brands from 28 countries were studied by Shotyk et al. [8]. Two of the brands had higher values than the MCLs of Japan $(2 \mu \mathrm{g} / \mathrm{l})$ which was mainly due to the use of $\mathrm{Sb}_{2} \mathrm{O}_{3}$ as the catalyst in the PET process. In 14 brands of bottled waters in Canada, $\mathrm{Sb}$ content during a 6 month storage period at room temperature increased approximately $19 \%$, while the 48 brands of 11 European countries demonstrated an increase of $90 \%$ under the same condition. The analysis of the underground spring water contained $1.7 \pm 0.4 \mathrm{ng} / \mathrm{L} \mathrm{Sb}$, following 6 month period of storage, the Canadian bottles Sb levels rose to $26.6 \pm 2.3 \mathrm{ng} / \mathrm{L}$, while the German bottled water demonstrated $28.1 \pm$ $3.8 \mathrm{ng} / \mathrm{L}[8]$.
In a research conducted by Baba et al. [14], the Co content levels were 7-11 ppb in sampled bottles, and the $\mathrm{Sb}$ levels reported were lower than $1 \mathrm{ppb}$, which were below the detection limit. However, it should be mentioned that to date, WHO, EPA and Turkish standards have defined no standard for Co levels. Moreover, in the present study, the concentration of Co levels, in all samples were below the limit of detection (LOD) [14].

\section{Conclusion}

The study has concluded that Antimony (Sb) may leach from the polyethylene terephthalate (PET) bottle into the bottled water. This particularly can be observed in water bottles which are stored at high temperatures for long periods. Furthermore, other trace elements should not be a concern, since these trace element concentrations with the exception of $\mathrm{Ba}$, were far below the recommended MCLs; also, during the storage period under different conditions the concentrations remained lower than the permitted levels. Hence, this study has concluded that to prevent the increase of $\mathrm{Sb}$ in bottled waters, it is strongly recommended that commercial markets not store the bottled waters at high temperatures for long periods, especially in summertime. Last of all, the consumer should not leave the bottled waters inside their vehicles' and/or closed areas due to the high temperatures which occur in these conditions.

\section{Competing interests}

The authors declare that they have no competing interests.

\section{Authors' contributions}

All authors read and approved the final manuscript.

\section{Acknowledgments}

This research was supported by a Tehran University of Medical Sciences (TUMS) and Health Services Grant (Project Number 91-01-27-17308 \& 93-0146-25274) and Center for Water Quality Research (CWQR), Institute for Environmental Research (IER), Tehran University of Medical Sciences, Grant (Project Number 93-01-46-25274).

\section{Author details}

${ }^{1}$ Department of Food Hygiene and Control, Faculty of Veterinary Medicine, Tehran University, Tehran, Iran. ${ }^{2}$ Department of Environmental Health Engineering, School of Public Health, Tehran University of Medical Sciences, Tehran, Iran. ${ }^{3}$ Center for Water Quality Research (CWQR), Institute for Environmental Research (IER), Tehran University of Medical Sciences, Tehran, Iran.

Received: 26 July 2014 Accepted: 26 October 2014 .

\section{References}

1. Venieri D, Vantarakis A, Komninou G, Papapetropoulou M: Microbiological evaluation of bottled non-carbonated ("still") water from domestic brands in Greece. Int J Food Microbiol 2006, 107:68-72.

2. Kokkinakis EN, Fragkiadakis GA, Kokkinaki AN: Monitoring microbiological quality of bottled water as suggested by HACCP methodology. Food Control 2008, 19:957-961.

3. Armas AB, Sutherland JP: A survey of the microbiological quality of bottled water sold in the UK and changes occurring during storage. Int J Food Microbiol 1999, 48:59-65. 
4. Yousefi Z, Enayati A, Mohammadpoor R: Parasitic contamination of wells drinking water in Mazandaran Province. Iranian J Environ Health Sci Eng 2009, 6:241-246.

5. Nunes Filho SAP, Sant'Ana AS, Cruz AG: Commercialization conditions and practices influence the microbiological quality of mineral waters. J Food Prot 2008, 71:1253-1257.

6. Cheng X, Shi H, Adams C, Ma Y: Assessment of metal contaminations leaching out from recycling plastic bottles upon treatments. Environ Sci Pollut Res 2010, 17:1323-1330.

7. Westerhoff P, Prapaipong P, Shock E, Hillaireau A: Antimony leaching from polyethylene terephthalate (PET) plastic used for bottled drinking water. Water Res 2008, 42:551-556.

8. Shotyk W, Krachler M: Contamination of bottled waters with antimony leaching from polyethylene terephthalate (PET) increases upon storage. Environ Sci Techno 2007, 41:1560-1563.

9. Soupioni MJ, Symeopoulos BD, Papaefthymiou HV: Determination of trace elements in bottled water in Greece by instrumental and radiochemical neutron activation analyses. J Radioanal Nucl Chem 2006, 268:441-444.

10. Ahmad M, Bajahlan A: Quality comparison of tap water vs. bottled water in the industrial city of Yanbu (Saudi Arabia). Environ Monit Assess 2009, 159:1-14.

11. Shotyk W, Krachler M, Chen B: Contamination of Canadian and European bottled waters with antimony from PET containers. J Environ Monit 2006, 8:288-292.

12. Keresztes S, Tatár E, Mihucz VG, Virág I, Majdik C, Záray G: Leaching of antimony from polyethylene terephthalate (PET) bottles into mineral water. Sci Total Environ 2009, 407:4731-4735.

13. Güler C: Evaluation of maximum contaminant levels in Turkish bottled drinking waters utilizing parameters reported on manufacturer's labeling and government-issued production licenses. J Food Compos Anal 2007, 20:262-272.

14. Baba A, Ereeş FS, Hıçsönmez Ü, Çam S, Özdılek HG: An assessment of the quality of various bottled mineral water marketed in Turkey. Environ Monit Assess 2008, 139:277-285.

Cite this article as: Molaee Aghaee et al: Effects of storage time and temperature on the antimony and some trace element release from polyethylene terephthalate (PET) into the bottled drinking water. Journal of Environmental Health Science \& Engineering 2014 12:133.

\section{Submit your next manuscript to BioMed Central and take full advantage of:}

- Convenient online submission

- Thorough peer review

- No space constraints or color figure charges

- Immediate publication on acceptance

- Inclusion in PubMed, CAS, Scopus and Google Scholar

- Research which is freely available for redistribution

Submit your manuscript at www.biomedcentral.com/submit 